\title{
Productive Performance of Crossbred Dairy Cows and constraints faced by dairy farmers in Mekelle, Ethiopia
}

\author{
Niraj Kumar ${ }^{1}$, Kbrom Tkui ${ }^{1}$, Desalew Tadesse Tegegne ${ }^{1}$ and \\ Awot Teklu Mebratu ${ }^{1}$ \\ (College of Veterinary Medicine, Mekelle University, Ethiopia)
}

\begin{abstract}
The study was conducted on 252 Holstein-Friesian (HF) crossbred cows maintained under farmer's managemental system in and around Mekelle (Ethiopia). A total of 72 small-scale dairy farm owners were randomly selected and interviewed with structured questionnaire to obtain information on the productive performance of crossbred cows. The results of the study showed that the mean of lactation length (LL) was $331.57 \pm 12.77$ days, peak yield (PY) was $12.15 \pm 0.82$ liters and the mean of lactation milk yield (LMY) was 2069.16 \pm 78.44 liters for crossbred cows. This study had also investigated constraints faced by the small-scale dairy farmers in Mekelle city. Non Availability of fodder round the year (72\%) was the major constraint followed by high costs on feeding \& Storage of feed (67\%), disease occurrence (58\%), inadequate knowledge about feeding (56\%), lack of timely AI (47\%), scarcity of capital (46\%), lack of timely Veterinary services (43\%), seasonality in demand for milk (40\%), high cost of medicine \& treatment (39\%), difficulty in heat detection (36\%), low price of milk (50\%), and Lack of credit facility (32\%) were constraints limiting dairy production in the study area.
\end{abstract}

Key words: Crossbred, Lactation length, Lactation milk yield, Mekelle, Peak yield.

\section{Introduction}

Ethiopia is believed to have the largest livestock population in Africa. This livestock sector has been contributing considerable portion to the economy of the country, and still promising to rally round the economic development of the country. The total cattle population for the country is estimated to be about 53.99 million. Out of this total cattle population, the female cattle constitute about 55.48 percent and the remaining 44.52 percent are male cattle [1]. On the other hand, the results obtained indicated that 98.95 percent of the total cattle in the country are local breeds. The remaining are hybrid and exotic breeds that accounted for about 0.94 percent and 0.11 percent, respectively [1].

Although the livestock sector has a significant contribution to the national economy, production per animal is extremely low. The average lactation milk production of the indigenous cows ranges from $494-850 \mathrm{~kg}$ under optimum management $[2,3]$. With an annual human population growth rate of $2.4 \%$, the present 77.4 million Ethiopia's human population will increase to about 149.3 million by the year 2040 [4]. Thus, the demand for animal products is expected to increase substantially. To meet the ever-increasing demand for milk, milk products and their contribution to economic growth, genetic improvement of the indigenous cattle has been proposed as one of the options. Genetic improvement of the indigenous cattle, basically focusing on crossbreeding has been practiced for the last five decades. The success of dairy production in general and crossbreeding programmes in particular needs to be monitored regularly by assessing the productive performance under the existing management system. However, information is limited about the productive performance of dairy cows in smallholder urban and peri-urban dairy farms in the tropics, particularly in Ethiopia [5].

Dairy farming plays an important role in social and economical livelihood of the smallholder farmers and pastoralists which produce and supply $98 \%$ of the total milk production of the country [6]. Despite the importance of dairying to the livelihood of farmers, there is little information on main constraints affecting dairy improvement in the study area. The present investigation was undertaken to study three important production trait such that lactation length (LL), lactation milk yield (LMY) and peak yield (PY) as well as constraints perceived by dairy farmers in rearing of crossbred cattle reared under private dairy unit in and around Mekelle (Ethiopia).

\subsection{Study area}

\section{Materials And Methods}

The study was conducted in and $10 \mathrm{Km}$ around Mekelle city of Tigray Region in the semiarid highlands of northern. Mekelle is the capital city of Tigray Region and located in the northern extremes of Ethiopia extending from $33^{\circ} 25^{1}$ to $39^{\circ} 38^{1}$ north latitude and from $36^{\circ} 27^{1}$ to $40^{\circ} 18^{1}$ east longitude at an average altitude of 2000 to 
2200 meters above sea level. The mean annual rain fall ranges from $11.3 \mathrm{~mm}$ to $39.1 \mathrm{~mm}$ and the temperature varies from $12^{\circ} \mathrm{C}$ (in November and December) to $27^{\circ} \mathrm{C}$ (in January and March). Mekelle enjoys humid and hot climate and $783 \mathrm{~km}$ from Addis Ababa [7].

\subsection{Sampling procedure and data analysis}

A total of 72 smallholder dairy farmers were interviewed randomly with scheduled questionnaire which was mainly based on the productive performance of HF crossbred dairy cows as well as and constraints faced by dairy farmers. A total of $252 \mathrm{HF}$ crossbred cows were included in this study were maintained under farmer's managemental system, located in a radius of about $10 \mathrm{kms}$ in and around Mekelle (Ethiopia). The questionnaire was developed in accordance with the objectives of the study and designed in a simple manner to get accurate information from the dairy farm owners. Each respondent was given a brief description about the nature and purpose of the study and the responses were recorded directly on the survey schedule.

The farmers under the study areas maintained cows under intensive management system in back-yard operation utilizing whatever space was available in the residential compound. The cows were managed in closed houses with different types of floor structure throughout the day. Cows were hand milked with twice per day milking frequency. The feed on which the animals were fed include straw, hay, chopped green fodder, milling by-products, concentrate mix and none-conventional feeds. Data were recorded like lactation length (LL), peak yield (PY) and lactation milk yield (LMY) as productive performance and constraints were enlisted as stated by the respondents. Descriptive statistics such as means and standard deviations were used.

\subsection{Lactation Length}

\section{Results And Discussions}

The mean LL in the present study was found to be $331.57 \pm 12.77$ days (table-1) which is in accordance with 333.9 days reported in crossbred cows in North Showa zone, Ethiopia [8]; 11.7 months in Central Highland of Ethiopia [9]; $334.64 \pm 1.99$ days in HF crossbred dairy cows maintained under farmers' managemental system in India [10]. In this study, the estimate of average lactation length in crossbred cows were longer than the standard lactation period ( 305 days), it could be explained as, indeed the crossbred cows continued to yield 2-3 litres of milk even in their late gestation and the small dairy owners did not practice force drying of their animals even beyond eight month of gestation to meet their sole objective of more and more milk. The mean LL in this study was larger than the mean of 9.13 \pm 1.99 months reported in Zebu X Holstein-Friesian crossbred dairy cows in Jimma Town, Oromia, Ethiopia [11]; 10.1 months in smallholder dairy system in Bahir Dar Zuria and Mecha Woredas, Northern Ethiopia [12]; 8.63 months in Yerer watershed Adalibeb woreda, Oromia region, Ethiopia [13]. The mean LL of this study was smaller than the mean of 350 days in local crossbred dairy cows in Arsi region in Ethiopia [14].

Table 1. Productive performance of crossbred dairy cows under smallholder condition in Mekelle Town.

\begin{tabular}{|l|l|}
\hline Parameter & Mean \pm S.E \\
\hline Lactation Length (days) & $331.57 \pm 12.77$ \\
\hline Lactation milk yield (liters) & $2069.16 \pm 78.44$ \\
\hline Peak milk yield (liters) & $12.15 \pm 0.82$ \\
\hline
\end{tabular}

\section{Lactation milk yield}

The mean LMY was found to be 2069.16 \pm 78.44 litres (table-1) in the present study which in accordance with 2055 litres reported in crossbred cows (1/2 Friesian X 1/2 Baraca) in Ethiopia [15]. The mean LMY of this study was larger than the mean of 1511.5 litres reported in crossbred dairy cows in North Showa zone of Ethiopia [8]; 1508 litres reported in Central Highlands of Ethiopia [9]. The mean LMY of this study was smaller than the mean of 2352 litres reported in crossbred cows (1/2 Friesian X 1/2 Zebu) [14] and 2333.63 litres in Zebu X Holstein-Friesian crossbred dairy cows in Jimma Town, Oromia, Ethiopia [11].

\subsection{Peak milk yield}

Achieving peak milk in the lactation curve has been a topic of discussion for a long time in dairy nutrition, and a benchmark used by dairymen as an indicator of early lactation and transition cow nutrition. Most cows achieve peak milk 45 to 90 days in milk and slowly lose production over time until dry-off. The mean PY was found to be $12.15 \pm 0.82$ litres (table-1) in the present study which was in accordance with $12.30 \pm 0.16 \mathrm{~kg}$. in HF crossbred dairy cows maintained under farmers' managemental system in India [10]. PY reported to be in range of $7.0 \mathrm{~kg}$ to $12.7 \mathrm{~kg}$ in two breed cross involving Boran and Horro with various level Holstein-Friesian in three locations (Bako, Debre Zeit and Holetta) in Ethiopia [16].

\subsection{Constraints of dairy production}

Dairy farming plays an important role in social and economical livelihood of the farmers. Ethiopia possesses enormous bovine wealth, but their per capita production is very low due to reasons that the farmers do 
not adopt improved dairy management practices at the desired level. Improved managemental practices have been prescribed by various research and development organizations to improve the dairy production but the farmers face various constraints in adoption of these practices. Constraints are the circumstances or the causes which prohibit the dairy farmers from adoption of the improved management practices. Here, constraints were studied under five categories i.e. Feeds and Feeding, Breeding, Veterinary / Health care service, financial problem and Marketing problems. Constraints faced by the dairy farmers in various areas of the dairying were recorded and are presented in the Table- 2 .

Table-2. Distribution of the dairy farmers on the basis of constraints faced in dairy farming (Total number of observations $=72$ )

\begin{tabular}{|c|c|c|}
\hline Constraints & Frequency & Percentage \\
\hline \multicolumn{3}{|l|}{ Feeds and Feeding } \\
\hline 1. Non availability of fodder round the year & 52 & 72 \\
\hline High costs on feeding \& storage of feed & 48 & 67 \\
\hline Inadequate knowledge about feeding & 40 & 56 \\
\hline \multicolumn{3}{|l|}{ Veterinary / Health care service } \\
\hline Disease occurrence & 42 & 58 \\
\hline Lack of timely veterinary services & 31 & 43 \\
\hline High cost of medicine \& treatment & 28 & 39 \\
\hline \multicolumn{3}{|l|}{ Breeding } \\
\hline Lack of timely AI & 34 & 47 \\
\hline Difficulty in heat detection & 26 & 36 \\
\hline \multicolumn{3}{|l|}{ Financial problems } \\
\hline Scarcity of capital & 33 & 46 \\
\hline Lack of credit facility & 23 & 32 \\
\hline \multicolumn{3}{|l|}{ Marketing problems } \\
\hline Seasonality in demand for milk & 29 & 40 \\
\hline Low price of milk & 24 & 33 \\
\hline
\end{tabular}

\subsubsection{Feeds and feeding}

The present study indicated that majority of farmers (72\%) reported non availability of fodder round the year followed by high cost on feeding and storage of feed (67\%) and inadequate knowledge about feeding $(56 \%)$ as the major feed and feeding related constraints in dairy farming (table-2). Availability and costs of feeds were also noted as major constraints in Shashemene-Dilla area, South Ethiopia [17]. Shortage of feed to be the major constraints to milk production, age at first calving and calving interval in crossbred (Zebu $\mathrm{x}$ Holstein-Friesian) dairy cows in Jimma town, Oromia State, Ethiopia [11]. Inadequate animal feed resources as one of the important challenges of Ethiopian dairy sector was also reported by other worker [18]. The feed supply is greatly influenced by the poor soil fertility and markedly reduced seasonal rainfall, leading to fluctuations both in terms of quantity and quality. Periodic shortfalls in feed availability, especially during the dry season, were the major constraints to livestock productivity. Prices of concentrate feeds were among the major problem dairy producers could not cope with, in all production systems. The problems of seasonal availability of roughage feeds can be minimized through conventional feed conservation practices like hay making, silage making and straw treatments so that roughage feed supplies would continue throughout the year.

\subsubsection{Veterinary / Health care service}

Diseases pose a major threat to dairy cattle production in the study area. Occurrence of disease in animals was a major constraint (table-2) for majority (58\%) of the dairy farmers since they lacked timely veterinary services $(43 \%)$. The farmers also pointed out about the high cost of medicine and treatment services $(39 \%)$. Even if there were veterinary services delivered by the office of agriculture, only few framers take their animals to the veterinary service. This was because of the fact that high cost for the medicine and low productivity of the animal which discourages farmers from use of veterinary services. In one study, it was indicated that one of many factors affecting the adoption of crossbred dairy cows were health problems great loss which might be improved by providing better management [19]. Climatic condition, poor nutritional status and low level of management contribute to a high incidence of cattle diseases, especially in the crossbred cattle. It was observed that farmers in the study area had no regular vaccination for the important contagious diseases on regular basis but treat their animals whenever the diseases occurred. The respondents said that diseases were impacting dairy production in many ways such as reduced body weight, reduced growth rate, low milk production and reproductive performance, mortality and high treatment cost.

In Ethiopia, the aggregate annual economic losses from animal diseases through direct mortality and reduced productive and reproductive performance were estimated at US\$150 million [20]. Many of the diseases 
in Ethiopia are still uncontrolled and are causing devastating effects both to the producers and to the national economy [21]. The prevalence of various animal diseases, tick borne diseases, internal parasites and infectious diseases affect dairy animals. The animal health services provided are inadequate; the cost of drugs while the diagnostic services are not readily available to the dairy farmer. An overall disease occurrence of 46.8 and 33.6 percent in urban and peri-urban dairying was reported in the central highlands [22].

\subsubsection{Breeding}

Artificial insemination plays an important role to increase the yielding capacity of cows and is the appropriate and cheapest way of genetic improvement and the realization of breeding programs has to be well organized and excited in a very reliable way and AI is fully functional when it is incorporated with good animal husbandry such as effective heat detection [23]. Artificial insemination, the most commonly used and valuable biotechnology has been used in Ethiopia over many decades [24]. Whether a producer uses artificial insemination or natural service, heat detection is a critical component of good reproductive management on the farm. The study revealed that (table-2) majority of the farmers (47\%) reported lack of timely Artificial Insemination (AI) facility followed by difficulty in heat detection (36\%). Majority of dairy cow owners (69.17\%) were not satisfied in different ways in the use of AI service during the time of weekends and holidays, this was due to shortage of AI technicians, shortage of input, distance from AI service and inefficiency of AI technicians while assessing problems associated with artificial insemination services was reported in West Gojjam Zone, Ethiopia [25]. The majority of dairy farmers (58\%) in the mixed crop-livestock production system and $6 \%$ of the urban producers were constrained on unavailability of AI services was reported in Shashemene-Dilla area, South Ethiopia [17].

\subsubsection{Financial problems}

Many farmers were aware of the existence of improved technologies that can offer them higher returns as compared with their conventional practices. However, most of the poor farmers do not have the financial means required to make the initial investment and acquire the associated technological inputs. Financial support or credit facilities to smallholder farmers who intend to enter into commercial dairy farming are very much limited [18]. The importance of establishing credit facilities is a crucial step to the country's dairy sector as indicated in the livestock development master plan [26]. The study revealed that many farmers (46\%) reported scarcity of capital followed by lack of credit facility (32\%) for dairy farm expansion, purchase of new stock, high cost of treatment of diseased animal, purchase of farm equipments and infrastructure development (table2). Limited availability of credit to the dairy farmers was also reported as one of the constraints in Ethiopian dairy sector [18] but it was not a major constraint of urban dairy farmers in Jimma Town of Ethiopia [27].

\subsubsection{Marketing problems}

Seasonal demand for milk and milk products was identified as one of the major problems (40\%) by dairy farmers (table-2) followed by low price of milk (33\%). There was no strong market chain between the rural producers and urban consumers. There were also no price regulatory mechanisms in place that can make such an important food item easily available and affordable to a large segment of the population. Producers were discouraged by high cost of inputs and lower milk price especially in urban areas of Mekelle city. Seasonality in demand for milk and milk products was identified as one of the major problems by $10.5 \%$ of the rural and $75 \%$ of the urban dairy producers, respectively [17]. Milk market related problems were also reported as one of the constraints in Ethiopian dairy sector [18]. For the seasonality in demand for milk and milk products, processing technologies which could extend the shelf-life of dairy products may remedy the problem. For potential dairy areas, where there is no market access, a milk collection scheme through establishment of milk marketing groups may alleviate the problem.

\section{Conclusion}

Dairy production was found to be an important enterprise and have the potential to be economically viable and greatly contribute to poverty alleviation, food security, improved family nutrition and income and employment generation. However, shortage as well as high cost of feed, occurrence of disease, expensive veterinary services, lack of timely AI, financial and marketing problems were the main constraints limiting dairy production in the study area. Thus, strategies designed to develop the dairy sector should take into account the existing production characteristics of the area and should focus on a systematic approach to alleviate the identified constraints by involving all stakeholders in the formulation and implementation of improvement strategies. 


\section{Acknowledgements} this study.

The authors are grateful to Dean and Head, College of Veterinary Medicine for general support during

\section{References}

[1] CSA. 2012/13. Agricultural sample survey. Report on livestock and livestock characteristics. The Federal Democratic republic of Ethiopia, Central Statistical Agency (CSA). Private Peasant Holdings. Statistical Bulletin 570, Addis Ababa, Ethiopia, April, 2013.

[2] EARO (Ethiopian Agriculture Research Organization). 1999. Livestock Research Strategy: Executive Summary. EARO, Addis Ababa, Ethiopia.

[3] Haile, A., Joshi, B.K., Workneh A., Azage T. and Singh, A. 2009. Genetic evaluation of Boran cattle and their crosses with Holstein Friesian in central Ethiopia: milk production traits. Animal. 3(4):486-493.

[4] FAO (Food and Agriculture Organization of the United Nations) data, 2005. Rome, Italy.

[5] Lobago, F., Bekana, M., Gustafsson, H. and Kindahl, H. 2007. Longitudinal observation on reproductive and lactation performances of smallholder crossbred dairy cattle in Fitche, Oromia region, central Ethiopia. Tropical Animal Health and Production, 39: 395403.

[6] YONAD, 2009. Value chain Analysis of Milk and Milk products in Borana pastoralist area, unpublished manuscript. 2009.

[7] MoM, 1998. Mekelle office of metrology. Info. Doc. Note. Mekelle, Ethiopia.

[8] Mulugeta, A. and Belayeneh A. 2013. Reproductive and lactation performances of dairy cows in Chacha Town and nearby selected kebeles, North Shoa Zone, Amhara Region, Ethiopia. World Journal of Agricultural Sciences, 1(1): 008-017

[9] Zelalem Y. 1999. Smallholder Milk Production Systems and Processing Techniques in the Central Highlands of Ethiopia. M.Sc. Thesis. Swedish University of Agricultural Sciences, Uppsala. pp: 15

[10] Kumar, N. 2005. Genetic analysis of milk production efficiency of cattle and buffalo in and around Darbhanga, Bihar. MVSc thesis submitted to Rajendra Agricultural University, Pusa, Bihar, India.

[11] Belay, D., K. Yisehak and G.P.J. Janssens, 2012. Productive and Reproductive Performance of Zebu X Holstein-Friesian Crossbred Dairy Cows in Jimma Town, Oromia, Ethiopia. Global Veterinaria 8 (1): 67-72.

[12] Asaminew and Eyasu, 2009. Smallholder dairy system and emergency of dairy cooperatives in Bahir Dar Zuria and Mecha Woredas, northern, Ethiopia. World J. Dairy and Food Sci., 4(2): 185-192.

[13] Mulugeta A. (2005). Characterization of dairy production systems of Yerer watershed Adalibeb woreda, Oromia region, Ethiopia. MSc Thesis. Dira Dawa, Ethiopia.

[14] Gabriel, H. Kiwuwa, M. Mohamed, Y. Kurtu, M. and Anderson D. (1983) Crossbred dairy cattle productivity in Arsi region, Ethiopia. ILCA research report.

[15] Million T. and Tadelle D. (2003). Milk production performance of zebu, HolsteinFriesian and their crosses in Ethiopia. Livestock research for rural development. (15)3. http://www.lrrd.org/lrrd15/3/Tade153.htm

[16] Gebregziabher G., Skorn K. 2013. Variance Components and Genetic Parameters for Milk Production and Lactation Pattern in an Ethiopian Multibreed Dairy Cattle Population. Asian Australas. J. Anim. Sci. 26(9) : 1237-1246

[17] Sintayehu Y., Fekadu B., Azage T. and Berhanu G. 2008. Dairy production, processing and marketing systems of ShashemeneDilla area, South Ethiopia. IPMS (Improving Productivity and Market Success) of Ethiopian Farmers Project Working Paper 9. ILRI (International Livestock Research Institute), Nairobi, Kenya. 62 pp.

[18] Yilma, Z., G.B., Emannuelle and S., Ameha. 2011. A Review of the Ethiopian Dairy Sector. Ed. Rudolf Fombad, Food and Agriculture Organization of the United Nations, Sub Regional Office for Eastern Africa (FAO/SFE), Addis Ababa, Ethiopia, pp 81.

[19] Berhanu B. 2002. Analysis of factors affecting the adoption of crossbred dairy cows in the central highlands of Ethiopia: The case of two districts in Selale zone. M.Sc. Thesis, Alemaya University, Dire Dawa, Ethiopia.

[20] Berhanu A. 2002. Welcome address: Animal health and poverty reduction strategies. In: proceedings of the 16th Annual Conference of the Ethiopian Veterinary Association (EVA), held 5-6 June, 2002, Ghion Hotel, Addis Ababa, Ethiopia, pp: 117-137.

[21] EARO (Ethiopian Agricultural Research Organization), 1996. Animal Health Research program strategy (draft document). Addis Ababa, Ethiopia.

[22] Lemma, T., Tegegne, A., Puskur, R., Ranjitha, P. and Hoekstra, D. 2008. Moving Ethiopian smallholder dairy along a sustainable commercialization path: missing links in the innovation systems: Improving Productivity and Market Success (IPMS) Project, ILRI, Addis Ababa, Ethiopia.

[23] Noakes, D.E., T.J. Parkinson and G.C.W. England, 2009. Veterinary Reproduction and Obstetrics. 8th ed. China, Sounders Elsevier, pp: $750-760$

[24] Webb, D.W., 2003. Artificial Insemination in Cattle. University of Florida, Gainesville. IFAS Extension, DS 58: 2-5.

[25] Zerihun B., Malede B. and Tewodros F. 2013. Assessment on Problems associated with Artificial Insemination Services in West Gojjam Zone, Ethiopia. Advances in Biological Research 7 (2): 59-66.

[26] GRM International BV. 2007. Livestock Development Master Plan Study. Phase I Report - Data Collection and Analysis. Volume 1 - Dairy.

[27] Belay, D., K. Yisehak and G.P.J. Janssens, 2011. Analysis of Constraints Facing Urban Dairy Farmers and Gender Responsibility in Animal Management in Jimma Town. Libyan Agriculture Research Center Journal International 2 (4): 155-160 